\title{
Giant Cell Arteritis
}

\author{
(D) Sunny Chi Lik Au, (D) Simon Tak Chuen Ko
}

Tung Wah Eastern Hospital, Clinic of Ophthalmology, Hong Kong, China

\section{Abstract}

A 76-year-old lady presented to emergency department for left eye sudden visual loss, and fundoscopy found cherry-red spot over the central macula with attenuated retinal vessels. Central retinal artery occlusion (CRAO) was diagnosed. She did not complain of new onset headache, but mild tenderness on palpation over left temporal area with vaguely weak pulsation detected. After the acute management of CRAO pharmacologically, rebreathing into paper bag, and ocular massage; patient underwent hyperbaric oxygen therapy hoping to salvage the ischemic retina while waiting for the erythrocyte sedimentation rate result. Result was $>100 \mathrm{~mm} / \mathrm{hr}$, and high dose oral steroid was started immediately. Superficial temporal artery biopsy (TAB), performed 2 days after steroid treatment, was diagnostic of giant cell arteritis (GCA). Positron emission tomography and computerized tomography scan revealed vasculitis over thoracic aorta, left common carotid and subclavian artery. Ocular imaging of CRAO, histology of GCA on TAB are discussed with the interesting images.

Keywords: Giant cell arteritis, central retinal artery occlusion, fundus fluorescein angiography, temporal artery biopsy
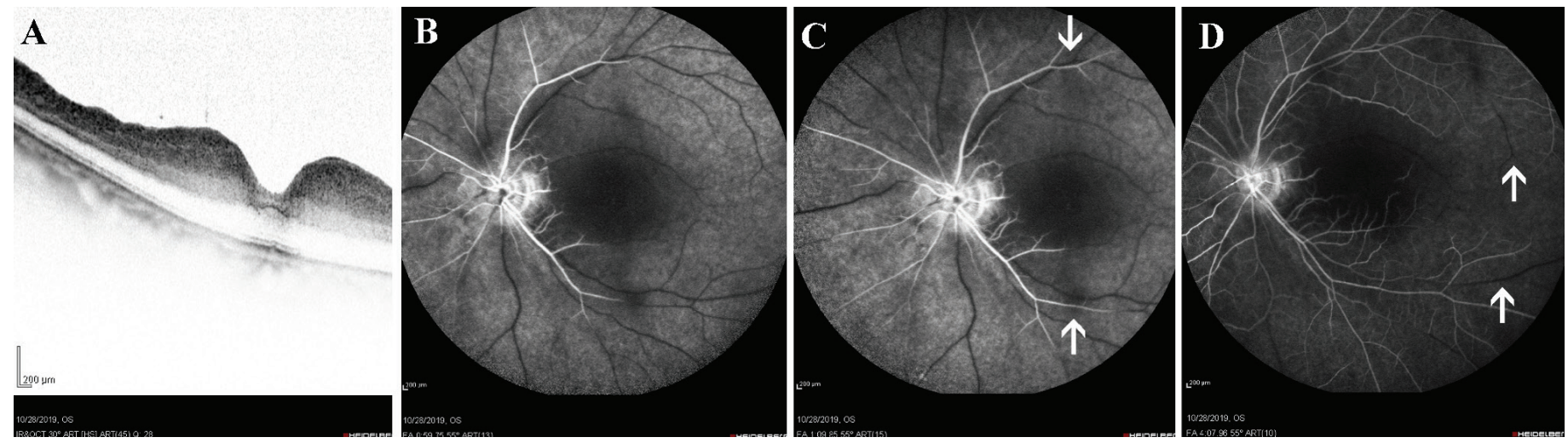

Figure 1. Fundus fluorescein angiography (FFA) is an investigation of the retinal vasculature with the injection of intravenous fluorescein dye (1), which appears as white colour on photography, whereas the non-perfused vasculature appears as black colour. Normal retinal arteries filling time is 10-13 seconds, while complete filling of veins at 16-20 seconds.

In our case, cross sectional view over the left eye foveal retina by optical coherence tomography (Figure $1 \mathrm{~A}$ ) showed inner retinal thickening from ischemia to almost double of normal. FFA photos taken at 10-20 seconds after the injection of dye were completely blackout. At around 1 minute (Figure 1B), FFA showed generalized delay and incomplete arterial filling of the retinal arteries, compatible with central retinal artery occlusion (CRAO). Figure 1C taken 10 seconds later showed minimal advancement of arterial filling only compared to filling position in Figure 1B (indicated by white arrows). Beyond 4 minutes (Figure 1D), not even all retinal veins were filled (indicated by white arrows) by the fluorescein indicating persistence absence of blood flow.

CRAO is a clinical diagnosis by fundoscopy for the presence of cherry-red spot over the central macula, generalized pale retina (edema caused by ischemia) with attenuated retinal vessels. Acute management of CRAO are pharmacologically to lower the intraocular pressure, rebreathing into paper bag and ocular massage (2). Underlying etiology for CRAO needs to be dealt with, such as giant cell arteritis (GCA) requires high dose steroid treatment (3). Hyperbaric oxygen therapy, if indicated and available, may help re-perfuse the ischemic retina by choroidal circulations (4).

Address for Correspondence: Sunny Chi Lik Au, Tung Wah Eastern Hospital, Clinic of Ophthalmology,

Received: 10.01 .2020

Hong Kong, China

Phone: +852 21626909 E-mail: kilihcua@gmail.com ORCID ID: orcid.org/0000-0002-5849-3317

Accepted: 03.02.2020

Cite this article as: Au SCL, Ko STC. Giant Cell Arteritis. Eur Arch Med Res 2020; 36 (2):159-61

๑Copyright 2020 by the University of Health Sciences Turkey, Prof. Dr. Cemil Taş̧ığlu City Hospital

European Archives of Medical Research published by Galenos Publishing House. 


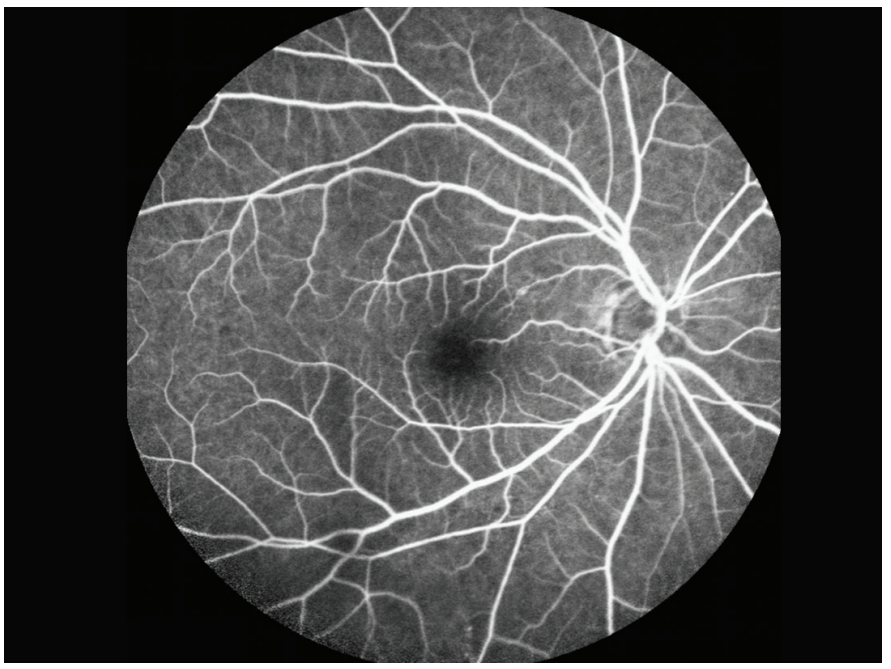

Figure 2. This FFA photo of the normal right eye taken at 48 seconds after the injection of dye (Figure 2) showed well perfused retina with filling of dye in both retinal arteries and veins.

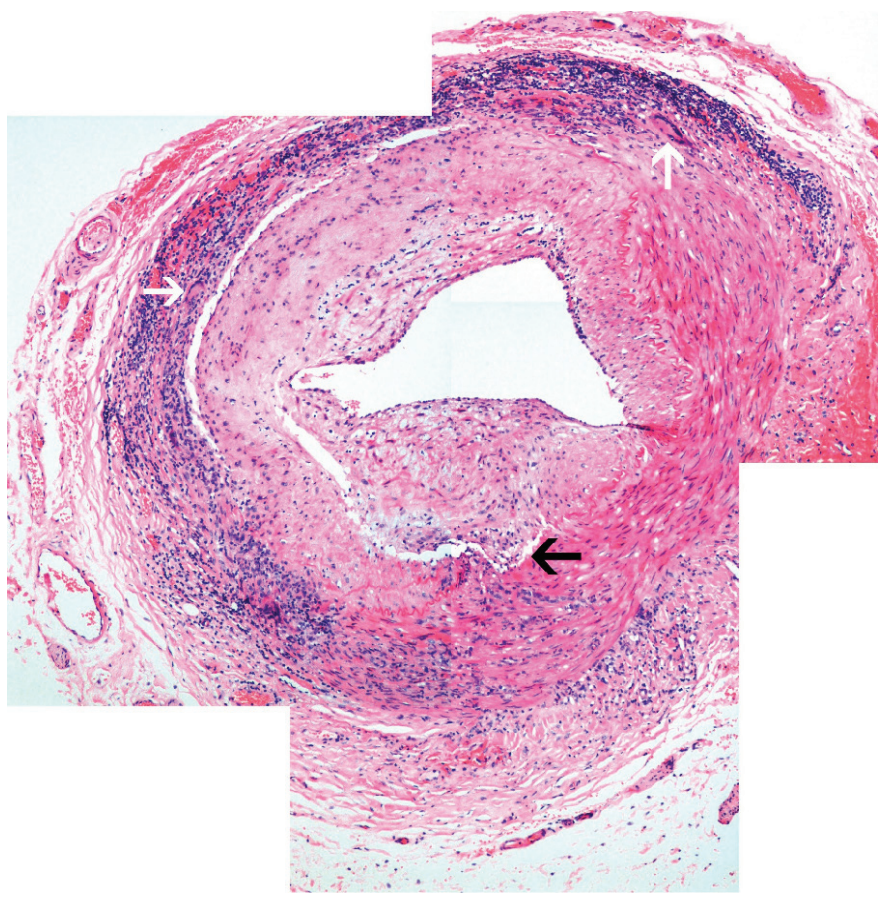

Figure 3. Superficial temporal artery biopsy (TAB) is one of the diagnostic criteria for GCA (5). This combined histology photo (Figure 3) from 3 high magnification (40x) films illustrated the cross sectional view of the temporal artery stained with haematoxylin and eosin. It showed narrowing of vascular lumen from concentric intimal hyperplasia (6). There was prominent transmural inflammatory infiltrate (highlighted as blue colour by the stain) accompanied by multinucleated giant cells (indicated by white arrows) at the level of internal elastic lamina, and loss thus fragmented internal elastic lamina (indicated by black arrow). Giving the name of GCA, giant cell is formed by fusion of epitheloid cells, activated macrophages, which the nuclei form semicircle in horseshoe configuration away from the eosinophilic centre of the giant cell. However, absence of giant cell on TAB specimen does not exclude GCA, as skip lesion is common in this type of large vessel vasculitis (7).

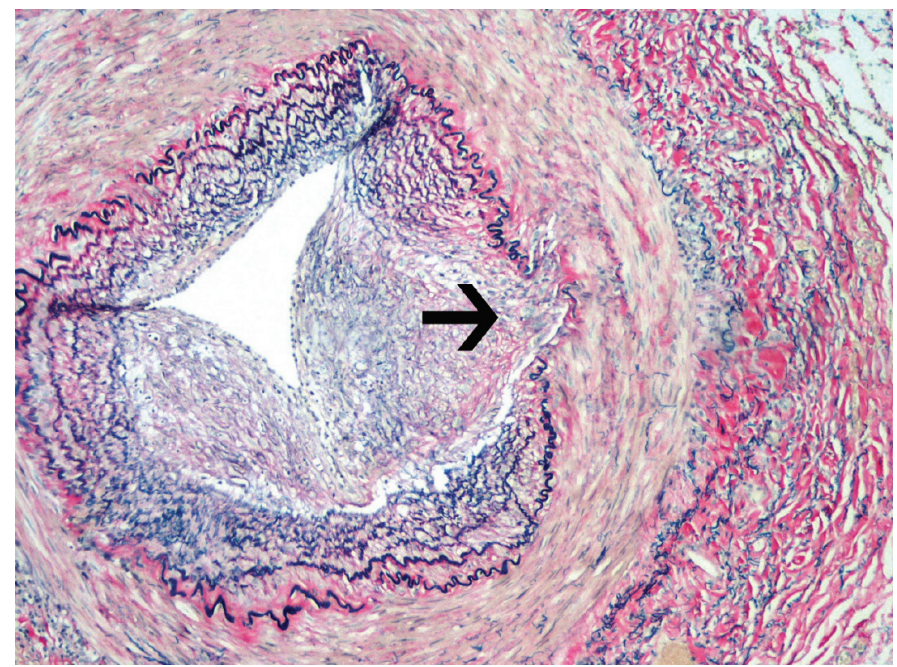

Figure 4. Elastic van Gieson stain is useful for highlighting the elastic fibers (8). In another level of cut over the TAB specimen (Figure 4), it demonstrated the disruption of internal elastic lamina at the site filled with inflammatory infiltrate (indicated by black arrow).

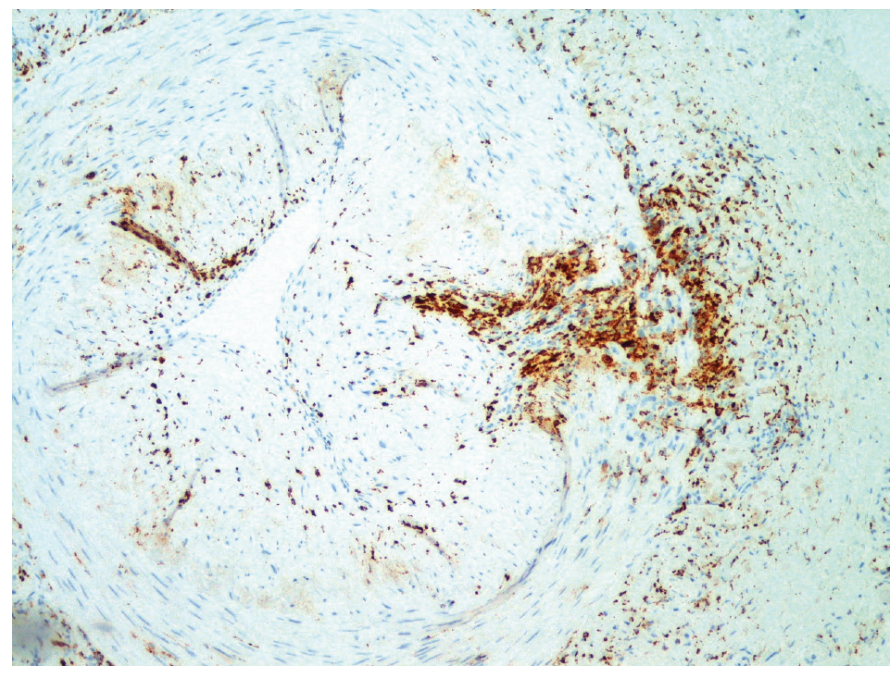

Figure 5. Immunohistochemistry staining over the TAB specimen for cluster of differentiation-68 (Figure 5) highlights the dense distribution of macrophages (brown colour) over the disruption of internal elastic lamina. 


\section{Ethics}

Informed Consent: Consent form was filled out by all participants.

Peer-review: Externally peer-reviewed.

Concept: S.C.L.A., Design: S.C.L.A., Data Collection or Processing: S.C.L.A., Analysis or Interpretation: S.C.L.A., Literature Search: S.C.L.A., S.T.C.K., Writing: S.C.L.A.

Conflict of Interest: No conflict of interest was declared by the authors.

Financial Disclosure: The authors declared that this study received no financial support.

\section{REFERENCES}

1. Gong $\mathrm{H}$, Song $\mathrm{Q}$, Wang L. Manifestations of central retinal artery occlusion revealed by fundus fluorescein angiography are associated with the degree of visual loss. Exp Ther Med 2016;11:2420-4.
2. Mehta N, Marco RD, Goldhardt R, Modi Y. Central Retinal Artery Occlusion: Acute Management and Treatment. Curr Ophthalmol Rep 2017;5:149-59.

3. Winkler A, True D. Giant Cell Arteritis: 2018 Review. Mo Med 2018;115:468-70.

4. Olson EA, Lentz K. Central Retinal Artery Occlusion: A Literature Review and the Rationale for Hyperbaric Oxygen Therapy. Mo Med 2016;113:537.

5. Hunder GG, Bloch DA, Michel BA, Stevens MB, Arend WP, Calabrese LH, et al. The American College of Rheumatology 1990 criteria for the classification of giant cell arteritis. Arthritis Rheum 1990;33:1122-8.

6. Wang AL, Raven ML, Surapaneni K, Albert DM. Studies on the Histopathology of Temporal Arteritis. Ocul Oncol Pathol 2017;3:60-5.

7. Poller DN, van Wyk Q, Jeffrey MJ. The importance of skip lesions in temporal arteritis J Clin Pathol 2000;53:137-9.

8. Foss F, Brown L. An elastic Van Gieson stain is unnecessary for the histological diagnosis of giant cell temporal arteritis. J Clin Pathol 2010;63:1077-9. 